\title{
Methylmalonic Aciduria
}

\section{An Inborn Error of Metabolism Leading to Chronic Metabolic Acidosis}

\author{
V. G. OBERHOLZER, B. LEVIN, E. ANN BURGESS, and WINIFRED F. YOUNG \\ From Queen Elizabeth Hospital for Children, Hackney Road, London E.2
}

Although metabolic acidosis from a variety of causes is very frequent in infancy, congenital acidosis appears to be extremely rare. Two unrelated cases of a new syndrome are now described with a congenital metabolic acidosis resulting from a block in the conversion of methylmalonic acid to succinic acid.

The first had persistent mild acidosis with acute episodes of severe metabolic acidosis during the first year of life. He was thought to have renal tubular acidosis, albeit atypical, and died during an acute episode at 2 years of age in 1959 . His disorder was always considered to have been similar to that of the later case, and this was confirmed 7 years after death by an examination of his stored plasma.

The second child, born in 1960, had persistent acidosis with acute exacerbations from the first week of life. She was found to have renal tubular acidosis, confirmed by the hydrogen ion clearance index, and treatment with alkalis was instituted, but her course was atypical. In one severe episode of acidosis it was noted that she was excreting a very acid urine during treatment, in spite of a normal blood $p \mathrm{H}$ and plasma bicarbonate. An analysis of the urine for organic acids revealed that she was excreting large amounts of methylmalonic acid, an intermediate in the metabolism of some amino acids and of fatty acids with an odd number of carbon atoms.

The effect of the metabolic block on protein and carbohydrate metabolism has also been studied, and preliminary investigations to elucidate the metabolic defect are presented.

\section{Case Reports}

Case 1. K.F., a boy, was the second born infant of healthy parents and has two normal sibs. His progress was satisfactory while on the breast for 7 weeks, but thereafter he began to suffer from intermittent vomiting

Received December 29, 1966. and constipation. At first he was hungry but later refused feeds.

In 1957 he was admitted to hospital aged 8 months, weighing $5.8 \mathrm{~kg}$. (123 $\mathrm{lb}$.), unable to sit up, and with generalized hypotonia, but no cause for his symptoms was found. He had persistent hepatomegaly but liver function tests were normal.

The vomiting, associated with upper respiratory tract infections recurred, and he had a raised blood urea and a metabolic acidosis. He was treated by alkali supplements, sodium citrate, and potassium acetate, to his milk feeds, but after an initial improvement, the acidosis recurred, and this was now attributed to renal tubular dysfunction. He was given a low protein diet and he began to gain weight on this treatment, the blood urea fell and the plasma $\mathrm{CO}_{2}$ level was normal and continued so after the alkali administration had been discontinued. $\mathrm{He}$ was discharged weighing $7 \mathrm{~kg}$. $\left(15 \frac{1}{2} \mathrm{lb}\right.$.), having been in hospital for 3 months.

One month later he was readmitted, respiratory infection having precipitated a recurrence of symptoms. The constitutional disturbance then failed to respond so well to symptomatic treatment. He had a persistent moderately raised blood urea with low urea clearances and some degree of metabolic acidosis, with an acid urine. However, he could concentrate his urine to a specific gravity of 1017 , and the pyelogram showed no abnormality of the renal tract.

From the age of 15 months, he was always on supplements of sodium citrate and potassium acetate and also on a restricted protein intake, but this treatment did not prevent recurring episodes of dehydration and metabolic acidosis, and progressive renal tubular dysfunction was postulated. When $1 \frac{1}{2}$ years old he weighed $9 \mathrm{~kg}$. $(20 \mathrm{lb}$.), and his condition was considered stable enough for him to be looked after at home.

Reappraisal at 21 months showed that the acidosis and increase in blood urea were present despite alkali administration, and the urine was acid. The dosage of alkalis was therefore increased and a higher fluid intake prescribed. Clinical improvement was now well sustained. When 2 years of age he developed respiratory infection and was admitted already in peripheral circulatory failure after vomiting for only 1 day, having been without alkalis and the high fluid intake on which he depended. Despite intravenous fluid and alkali 
administration, the blood urea, which was $184 \mathrm{mg} . / 100$ $\mathrm{ml}$. on admission, rose to $204 \mathrm{mg}$., plasma $\mathrm{CO}_{2}$ content fell from 5.6 to $3.4 \mathrm{mEq} / 1$. and $\mathrm{Cl}$ from 91 to $75 \mathrm{mEq} / \mathrm{l}$. Although the plasma $\mathrm{CO}_{2}$ content then rose to $14 \mathrm{mEq} / 1$., he failed to respond clinically, developed anuria, and his convulsions became difficult to control. He died 2 days after admission.

The necropsy was performed by Dr. N. E. France, who reported as follows.

'Pneumonia due to monilia infection was found. Both kidneys were small (weight $28 \mathrm{~g}$. and $29 \mathrm{~g}$.), and had scarred stripped surfaces, the thin cortex showing poorly defined architecture. Microscopically, they showed a curious appearance with infantile type glomeruli and diminutive tubules arranged in irregular areas showing mildly increased interstitial tissue and a little lymphocytic infiltration. The tissue between these areas consisted of normal tubules with few glomeruli. Occasional tubules were dilated and some contained hyaline casts. The liver showed marked fatty change.'

Case 2. S.H. was the third infant of healthy parents, and has one normal female sib. She was admitted to hospital when 3 days old with a gross initial weight loss from vomiting, and at 7 days was transferred to Queen Elizabeth Hospital for Children with suspected intestinal obstruction. She was a grossly dehydrated infant with abdominal distension, and at 5 days of age had been passing 'diarrhoeal' stools. There was an acidosis which was consistent with the symptoms, and the finding of Esch. coli 0.26 in the stool suggested gastro-enteritis as the cause of the illness, which was treated accordingly.

During the next month she had intermittent vomiting, constipation, and variable abdominal distension without $x$-ray evidence of intestinal obstruction. A metabolic disorder was considered as the possible cause of her illness, but because of the relatively mild degree of acidosis, the symptoms were thought to be more probably alimentary in origin, possibly a partial or intermittent obstruction of the bowel. Since she began to gain weight well during the third month she was discharged from hospital.

One month later she was readmitted for recurrence of vomiting and constipation. She was noted to be hypotonic. Pyuria was found but a congenital renal defect was excluded by $x$-ray examination. After initial improvement, the vomiting with acidosis recurred. Her clinical progress was slow, despite a good appetite, and there was little to account for her failure to thrive. It was recognized that her clinical course resembled that of the first case, and she was given a high fluid, low protein intake with supplements of sodium citrate and potassium acetate. It was noted that her urine remained acid even when the plasma $\mathrm{CO}_{2}$ content exceeded 20 $\mathrm{mEq} / \mathrm{l}$. She began to gain weight between setbacks associated with severe vomiting, but she appeared to be retarded physically and mentally, was unable to sit up, and hepatic enlargement was noted.

During the latter part of the first year of life she had 5 severe episodes of vomiting with dehydration associated with slight or absent provocation from intercurrent infection. Further investigations showed that she had generalized renal impairment with low urea and creatinine clearances in addition to a low hydrogen ion clearance index. However, the $x$-ray appearances of the kidneys were still normal.

Although her renal function was deteriorating at this stage, she was beginning to thrive, but was still unable to sit up and weighed only $7 \cdot 25 \mathrm{~kg}$. (16 lb.) at 1 year. She was considered sufficiently stable to go home and was discharged on a high fluid, restricted protein intake with added sodium citrate and potassium acetate, $60 \mathrm{mEq}$ of each daily. Thereafter, she made surprisingly good progress and at 2 years weighed $13 \mathrm{~kg}$. $(29 \mathrm{lb}$.), and was walking well; Dr. Agatha Bowley reported that she might prove less mentally retarded than appeared from her performance at that time.

She was admitted to hospital again during the fourth year of age with a severe clinical episode. This responded well to symptomatic treatment. Her mother was beginning to be able to control episodes of upper respiratory tract infections at home by giving, at their onset, ample drinks of sweet clear fluids, and she had sustained uncomplicated mumps without constitutional disturbance. She was inquisitive and sociable and considered to be ahead of her sib at the same age. Dr. Bowley's reassessment during the fifth year of life showed her IQ to be 100 (Merrill-Palmer Scale). $X$-ray appearances of the renal tract were normal and the urea and creatinine clearances were improving. Alkali therapy was unaltered throughout this period.

When $5 \frac{1}{2}$ years old, she was readmitted in an episode of severe vomiting requiring intravenous fluid therapy. Vomiting persisted even after the acidosis had been controlled. Again it was noted that the urine was acid at a time when the plasma standard bicarbonate was over $20 \mathrm{mEq} / 1$.

During the past year she has had a similar episode requiring hospital treatment. It is now well recognized that when she develops uncontrollable vomiting, it quickly leads to severe acidosis with air hunger and needs to be treated immediately by intravenous glucose and alkali solutions. She still requires alkali therapy which is given in the form of sodium and potassium bicarbonate, $15 \mathrm{mEq}$ of each, three times daily. In other respects she is now a well girl, her height and weight being normal for her age.

Family History. There was no history of fits, mental defect, or other relevant disease in the family of Case 1.

In Case 2 there is one healthy sib now 8 years old, who had a single fit when 7 years old. One male sib died at 4 months: he had failed to thrive and suffered from vomiting. At necropsy, the adrenals and thyroid were noted to be small. The cause of death was thought to be 'metabolic insufficiency' and 'congenital oesophageal neuromuscular abnormality'. A paternal uncle is a mongol.

\section{Laboratory Investigations}

Methods. Plasma electrolytes were determined by conventional micro or ultramicro methods; plasma and 
urinary ketones by the method of Tanayama and $\mathrm{Ui}$ (1963); blood pyruvate and lactate, and plasma $\alpha$ ketoglutarate by a micro modification of the enzymatic method published by C. F. Boehringer \& Soehne, Darmstadt.

Since the key observations were made on the second case, her laboratory findings will be described first.

Routine investigations. Case 2. Apart from the low $\mathrm{CO}_{2}$ content, other plasma electrolyte levels were usually within normal limits. Her first episode of severe metabolic acidosis, when the $\mathrm{CO}_{2}$ content was as low as $6 \mathrm{mEq} / \mathrm{l}$., began on the 4 th day of life and was associated with a mild gastro-intestinal infection with Esch. coli 0.26 . Similar low $\mathrm{CO}_{2}$ levels were found in subsequent episodes of metabolic acidosis, despite oral alkali therapy. Serum or plasma levels of total protein, albumin and globulin, calcium, phosphorus, alkaline phosphatase, and cholesterol at varying times during the first two years of life were generally within normal limits. Plasma magnesium estimated when she was 6 years old was low, $1.7 \mathrm{mg} . / 100 \mathrm{ml}$. Paper chromatography of the urine showed no abnormality in amino acid excretion. No oxalate could be detected on the examination of several urine specimens.

During the first few months of life there was no evidence of anaemia, but thereafter $\mathrm{Hb}$ level tended to be somewhat low, about $10.5 \mathrm{~g} . / 100 \mathrm{ml}$., with a colour index of 1 or slightly less, and this level persists. There is no evidence of megaloblastic anaemia.

Case 1. This boy was found to have a low $\mathrm{CO}_{2}$ content, $12 \mathrm{mEq} / 1$., and ketone bodies in the urine during a mild infection, 6 weeks after admission to hospital. This responded to treatment with sodium lactate over several weeks. Although the $\mathrm{CO}_{2}$ content appeared to remain for a short time within normal limits without alkali supplements, a metabolic acidosis was again noted a few weeks later, and thereafter alkali therapy was always required. The plasma $\mathrm{CO}_{2}$ content did not at any time fall below $12 \mathrm{mEq} / \mathrm{l}$., except during the terminal illness, when it was as low as $5.6 \mathrm{mEq} / \mathrm{l}$. The plasma sodium and potassium levels were always within normal limits, as was the plasma chloride which was never raised, and during the period was actually very low when the plasma $\mathrm{CO}_{2}$ content was similarly diminished.

Other routine investigations included serum calcium, phosphorus, and phosphatase, total protein, albumin and globulin, and cholesterol, which were all within normal limits. Urinary coproporphyrins were not detected. The stool trypsin was normal, and a 5-day fat balance revealed a $97 \%$ fat absorption. Less than $0.2 \mathrm{mg}$. oxalate was excreted in 24 hours, thus excluding oxalosis as a cause of the persistent acidosis.

A moderate aminoaciduria, with a marked glycine band, was noted on three occasions in the first 9 months of life, the proportion of amino nitrogen to total nitrogen being $9.4 \%, 6 \cdot 1 \%$, and $13.1 \%$ compared with a normal value for the method used of up to $5 \%$. The urinary indole pattern was normal.

Liver function tests. Case 2. These were carried out during periods when the liver was enlarged from one to four fingers breadth. The thymol turbidity and flocculation, zinc sulphate turbidity, $\gamma$-globulin turbidity, and serum bilirubin were normal. However, the transaminases were slightly raised on two occasions, but thereafter the levels returned to normal.

Case 1. Although the liver was always enlarged, there was no evidence of impaired function. Jaundice was absent, and the thymol turbidity, zinc sulphate turbidity, and $\gamma$-globulin turbidity were all normal.

Renal function tests. Case 2. During periods of acidosis, the urine was always acid, and it could be acid even when the plasma $\mathrm{CO}_{2}$ content was normal, for example during an acute episode of metabolic acidosis in the first 6 months of life the urine was acid when the plasma $\mathrm{CO}_{2}$ had risen to $24 \mathrm{mEq} / \mathrm{l}$. on treatment with alkalis. This was not always the case, however, and the urine could be neutral or alkaline when the plasma $\mathrm{CO}_{2}$ content was normal or high on alkali therapy.

The blood urea, estimated on numerous occasions, varied between $20 \mathrm{mg}$. and $60 \mathrm{mg}$. $/ 100 \mathrm{ml}$., mostly over $40 \mathrm{mg}$., but rose to levels as high as $135 \mathrm{mg}$. during periods of more severe acidosis. Urea and creatinine clearances determined on a number of occasions between the first and sixth year of life were considered to be low for the child's age, the creatinine clearance being probably less impaired than that of urea. Thus, at 10 months of age the urea and creatinine clearances were, respectively, $12 \cdot 3$ and $18 \cdot 0 \mathrm{ml} . / \mathrm{min} . \mathrm{m}^{2}$ and at 17 months, $22 \cdot 1$ and $42 \cdot 1 \mathrm{ml} . / \mathrm{min} . \mathrm{m}^{2}$ The hydrogen ion index (Peonides,

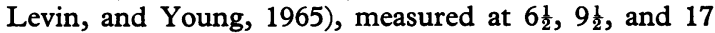
months of age after a short period off alkalis, was very low on each occasion, $0.44,0 \cdot 26$, and 0.59 , compared with a normal value of $1 \cdot 2$ or more. The clearance of phosphorus was within normal limits as was the calcium/ creatinine ratio.

Case 1. The urine was nearly always acid, and invariably so during periods of more severe acidosis, the $p \mathrm{H}$ being as low as $4 \cdot 8$ when the plasma $\mathrm{CO}_{2}$ content was $12.0 \mathrm{mEq} / 1$. Terminally, when renal failure was severe, as shown by a blood urea of $204 \mathrm{mg} . / 100 \mathrm{ml}$., and serum phosphorus of $15.0 \mathrm{mg} . / 100 \mathrm{ml}$., the urine $p \mathrm{H}$ was 4.8 , when the plasma $\mathrm{CO}_{2}$ content had fallen to $5.6 \mathrm{mEq} / \mathrm{l}$. Although the hydrogen ion clearance index was not determined, these results suggested that the ability of the kidney to acidify the urine in the face of a metabolic acidosis was not impaired. Additional evidence for this is given by the rate of ammonia excretion which was $25 \cdot 6 \mu \mathrm{Eq} / \mathrm{min} .1 \cdot 73$ sq. $\mathrm{m}$., when the urinary $p \mathrm{H}$ was $5 \cdot 0$, a correlation well within normal range (Peonides et al., 1965), as well as by the relation of plasma $\mathrm{CO}_{2}$ content to urinary $p \mathrm{H}$ which was also normal (Peonides et al., 1965).

As in Case 2, the urine could be acid, below $p \mathrm{H} 6 \cdot 0$, even when the plasma $\mathrm{CO}_{2}$ content was as high as $28 \cdot 5$ $\mathrm{mEq} / \mathrm{l}$. when the patient was under treatment with alkalis.

On several occasions, the maximum urinary specific gravity on thirsting was found to be no greater than 1017. 
The urea clearance was impaired, $15.0 \mathrm{ml} / \mathrm{min} . \mathrm{m}^{2}$ at $8 \frac{1}{2}$ months of age, and 16.5 when he was $15 \frac{1}{2}$ months of age.

Ketosis and ketone bodies in plasma. Case 2. The level of total ketone bodies in the plasma varied between $1.2 \mathrm{mg}$. and $3.5 \mathrm{mg} . / 100 \mathrm{ml}$. under fasting conditions, compared with a normal level of up to $2 \mathrm{mg} . / 100 \mathrm{ml}$. During one period of acute illness the level rose from $2.6 \mathrm{mg}$. up to $50 \mathrm{mg}$. $/ 100 \mathrm{ml}$. at the height of illness.

Case 1. The plasma ketone bodies estimated on only one occasion (see below) were $4 \cdot 2 \mathrm{mg}$. $/ 100 \mathrm{ml}$.

Investigation of urinary organic acids. These were isolated from the urine in Case 2 by the method of Nordmann, Gauchery, du Ruisseau, Thomas, and Nordmann (1954).

Urine $(5 \mathrm{ml}$.) was applied to a $0.6 \mathrm{~cm} . \times 10 \mathrm{~cm}$. column of Dowex 2X8, 5-100 mesh in the formate form, and after washing with water, the organic acids were eluted with $10 \mathrm{ml} .12 \mathrm{~N}$ formic acid. The eluate was taken to dryness in a rotary evaporator, and the residue dissolved in $0.4 \mathrm{ml} .20 \%$ isopropanol. Usually $0.02 \mathrm{ml}$. was subjected to one-way paper chromatography with ethyl alcohol-ammonia-water as solvent system, bromocresol green being used as indicator. In addition to the usual small amounts of organic acids normally found in urine, a large amount of an unknown organic acid was detected, with an $R_{f}$ value between that of malic and $\alpha$-ketoglutaric acids. Using propanol-formic acidcineol-water as solvent system, the unknown acid had an $\mathbf{R}_{\mathbf{f}}$ value almost identical with that of aconitic acid; however, it exhibited no absorption when the dried chromatogram was examined under ultraviolet light. The unknown, after staining with p-dimethylaminobenzaldehyde in acetic anhydride, gave only a pale yellow band, and with p-dinitrophenylhydrazine followed by potassium hydroxide solution there was no reaction; silver nitrate followed by sodium hydroxide was not reduced. There was no reaction with ammonium vanadate. The unknown acid was found to be easily extracted with ether from an acid aqueous solution. These results suggested that it was a dicarboxylic acid but not succinic, malonic, aconitic, citric, $\alpha$-ketoglutaric, tartaric, or glyoxylic acids. Since it did not appear to be one of the organic acids commonly found in the urine, it seemed probable that it might be one of the substituted dicarboxylic acids which have been detected in normal human urine. That it was a substituted malonic acid was confirmed by its colour reaction with diazotized p-nitroaniline (Giorgio and Plaut, 1965) adapted as a spot test on paper after chromatography. Comparison with the $\mathbf{R}_{\mathbf{f}}$ values of methylmalonic and ethylmalonic acids suggested that it was the former.

\section{Isolation of Unknown Organic Acid and Proof of Identity with Methylmalonic Acid}

Approximately $200 \mathrm{ml}$. urine was made alkaline with $\mathrm{NaOH}$ and concentrated to half its volume and filtered. The filtrate was acidified to approximately $p \mathrm{H} 3$ with con- centrated formic acid solution, allowed to stand overnight at $4^{\circ} \mathrm{C}$., and again filtered. The filtrate was applied to a column $1 \mathrm{~cm}$. diameter, containing about $40 \mathrm{ml}$. of Amberlite CG 400, mesh 200-400 in the formate form. The column was washed with $200 \mathrm{ml}$. water, and the organic acids eluted with $200 \mathrm{ml} .12 \mathrm{~N}$ formic acid. The light brown acid eluate was decolorized by standing for 30 minutes with about $50 \mathrm{mg}$. activated charcoal, the filtered solution was reduced to about $5 \mathrm{ml}$. in a rotary evaporator at $40^{\circ} \mathrm{C}$., and then extracted three times with $50 \mathrm{ml}$. ether. The combined ether extracts were taken to dryness by first boiling off the ether, and then keeping in vacuo over solid $\mathrm{NaOH}$. The dried residue was thrice recrystallized from acetic acid-toluene mixture $(10: 90 \mathrm{v} / \mathrm{v}$.$) .$

The proof of identity of the unknown acid with methylmalonic acid rested on the following. The mobilities found by one-way paper chromatography, using as solvent systems n-butanol-acetic acid-water (4:1:5); n-propanol-eucalyptol-formic acid (5:5:2); ethanol-ammonia sp. gr. $0 \cdot 88$-water (160: $6: 34)$; 3-methyl-n-butanol-formic acid-water (150: $45: 200)$; 2-ethyl-n-butanol-5M aqueous formic acid (2:3); coincided with those of an authentic specimen of methylmalonic acid. The absorption spectrum of the coloured compound formed with diazotized p-nitroaniline was identical with that obtained from the known acid. The melting point with decomposition of the compound obtained from the urine was $132-133^{\circ} \mathrm{C}$., the same as that of the authentic acid. Finally, an elementary analysis of the substance isolated from the urine agreed with the expected theoretical values $(C=41 \cdot 31 \%$, $\mathrm{H}=5 \cdot 07 \%$; theoretical $\mathrm{C}=40 \cdot 7 \%, \mathrm{H}=5 \cdot 12 \%$ ).

For the estimation of methylmalonic acid see the Appendix.

\section{Levels of Methylmalonic Acid in Urine, Plasma, and Cerebrospinal Fluid}

Case 2. The urinary excretion of methylmalonic acid was measured on a number of occasions when the child was 6 years old. Under fasting conditions the concentration varied from 0.83 to $1.05 \mathrm{~g} . / 100 \mathrm{ml}$., and the 24 -hour excretion on two separate days while she was on sodium citrate therapy was $5 \cdot 76 \mathrm{~g}$. and $5 \cdot 34 \mathrm{~g}$. per day. The plasma level determined under fasting conditions varied from $18 \cdot 7 \mathrm{mg}$. to $27 \cdot 6 \mathrm{mg}$. $/ 100 \mathrm{ml}$. The renal clearance was also measured on one occasion simultaneously with that of urea and creatinine. The value was between that of creatinine and urea, which makes it probable that there is some renal tubular reabsorption of the acid (Table). The level in CSF measured on one occasion when she was 6 years old was $18.6 \mathrm{mg}$. $/ 100 \mathrm{ml}$., the plasma level at the same time being $18.3 \mathrm{mg} . / 100 \mathrm{ml}$.

Case 1. This was determined 7 years after death in a specimen of plasma kept frozen for that time. It had been collected from the patient when he was 19 months old. At the time he was relatively well, though having a moderately severe acidosis, the plasma $\mathrm{CO}_{2}$ content being $14.5 \mathrm{mEq} / 1$., in spite of having $1 \mathrm{~g}$. each of sodium citrate and potassium acetate daily. The level of 
TABLE

Levels of Methylmalonic Acid in Cerebrospinal Fluid, Plasma and Urine and Renal Clearance (Case 2)

(Mean values on one day)

\begin{tabular}{|c|c|c|c|c|}
\hline & & $\begin{array}{c}\text { Methylmalonic } \\
\text { Acid } \\
\text { (mg. } / 100 \mathrm{ml} .)\end{array}$ & $\begin{array}{c}\text { Creatinine } \\
(\mathrm{mg} . / 100 \mathrm{ml} .)\end{array}$ & $\begin{array}{c}\text { Urea } \\
\text { (mg./100 ml.) }\end{array}$ \\
\hline $\begin{array}{l}\text { CSF } \\
\text { Plasma } \\
\text { Urine }\end{array}$ & $\begin{array}{ll}\cdots & \cdots \\
\cdots & \cdots \\
\cdots & \cdots\end{array}$ & $\begin{array}{l}18 \cdot 6 \\
18 \cdot 3 \\
410\end{array}$ & $\begin{array}{c}\overline{0 \cdot 83} \\
23 \cdot 8\end{array}$ & $\begin{array}{r}4 \overline{7} \\
610\end{array}$ \\
\hline \multicolumn{2}{|c|}{$\begin{array}{l}\text { Renal clearance } \\
(\mathrm{ml} . / \mathrm{min} . \mathrm{sq} . \mathrm{m} .)\end{array}$} & $47 \cdot 1$ & $60 \cdot 5$ & $27 \cdot 4$ \\
\hline
\end{tabular}

methylmalonic acid was found to be $22.5 \mathrm{mg} . / 100 \mathrm{ml}$. and the ketone bodies $4 \cdot 2 \mathrm{mg} . / 100 \mathrm{ml}$.

\section{Metabolic Tests (Case 2)}

Glucose loading test. A glucose tolerance test with $1 \cdot 75 \mathrm{~g} . / \mathrm{kg}$. given orally showed a normal absorption and utilization of glucose. The blood or plasma levels of lactate, pyruvate, $\alpha$-ketoglutarate, non-esterified fatty acids, ketone bodies, and methylmalonic acid were also estimated at intervals after the dose was given and the results are shown in Fig. 1. Lactate, pyruvate, and non-esterified fatty acids vary as expected with the glucose level. The level of methylmalonic acid, however, rose slightly, and then fell, while that of the ketone bodies fell to half the initial level and then rose again; the $\alpha$-ketoglutarate level was essentially unchanged and within normal limits. There was no change in the rate of excretion of methylmalonic acid in the urine.

Glucagon test. The administration of $0.3 \mathrm{mg}$. glucagon intramuscularly resulted in a normal rise in blood glucose followed by a fall, which continued for at least 5 hours when it was still below the fasting level. There was, as expected, an immediate fall in plasma free fatty acids. Although the pyruvate was essentially unchanged, the blood lactate level surprisingly fell significantly (Fig. 2).

Protein loading test. Since methylmalonic acid is an intermediary metabolite in the metabolism of some amino acids, it seemed desirable to assess the effect of

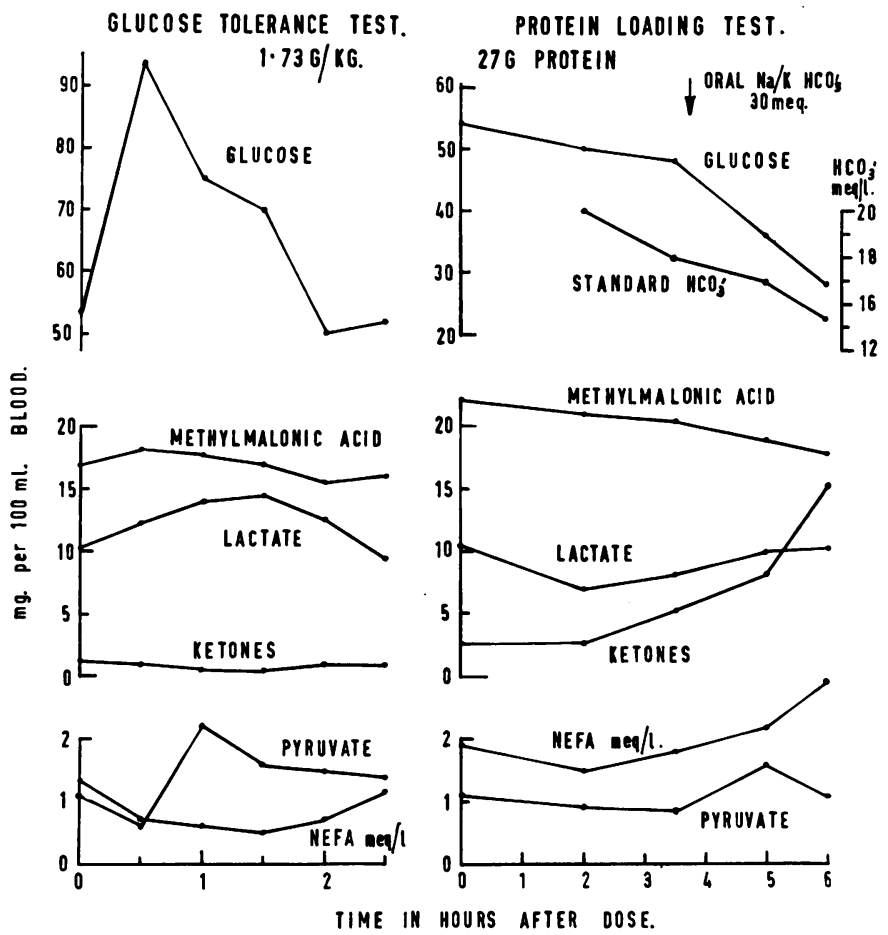

FIG. 1 left.-(Case 2) Changes in levels of blood glucose, lactate, pyruvate, plasma non-esterified fatty acids, ketones, and methylmalonic acid following the ingestion of glucose $(1 \cdot 75 \mathrm{~g} . / \mathrm{kg}$.$) .$

FIG. 1 right.-(Case 2) Changes in levels of blood glucose, lactate, pyruvate, plasma non-esterified fatty acids, ketones, methylmalonic acid, and standard bicarbonate following the ingestion of protein (27 g.). Note the consistent fall in blood glucose and plasma standard bicarbonate and the rise in plasma ketones. 
ingestion of protein. A meal of fish and cheese containing an estimated amount of about $27 \mathrm{~g}$. protein was therefore given and the same series of estimations as for the glucose test was performed. The results are shown in Fig. 1. The blood glucose fell during the 6-hour period from $64 \mathrm{mg}$. to $29 \mathrm{mg}$. $/ 100 \mathrm{ml}$., with a corresponding marked rise in plasma non-esterified fatty acids. Surprisingly, there was a fall in plasma methylmalonic acid level, though the plasma ketone level increased considerably. There was also a rise in $\alpha$-ketoglutarate from $0.20 \mathrm{mg}$. to $0.28 \mathrm{mg} . / 100 \mathrm{ml}$. Despite the fall in blood level, there was a significant increase in the rate of urinary excretion of methylmalonic acid in the last hour, suggesting that there had been an increased formation of this acid. During the 6-hour period of the test the plasma $p \mathrm{H}$ remained almost the same, but a moderate acidosis developed, as indicated by a fall in the plasma standard bicarbonate level, and this was despite the fact that she was given her usual dose of $15 \mathrm{mEq}$ each of sodium and potassium bicarbonate during the test.

Valine. Since this amino acid forms methylmalonic acid during metabolism, a test dose of $2 \mathrm{~g}$. I-valine was given orally. As in the previous test, there was a severe decline, from $61 \mathrm{mg}$. to $27 \mathrm{mg}$. $/ 100 \mathrm{ml}$. in the blood glucose level, with little change in the blood levels of lactate and pyruvate (Fig. 3). Plasma non-esterified fatty acids, however, rose coincidentally with the fall in blood glucose. Methylmalonic acid, after an initial fall,

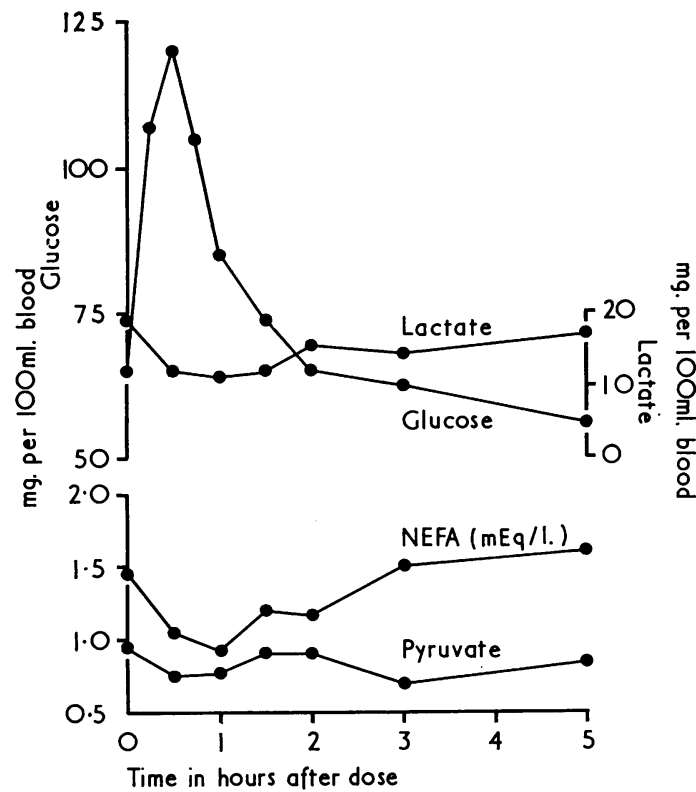

FIG. 2.-(Case 2) Changes in levels of blood glucose, lactate, and plasma non-esterified fatty acids after intramuscular injection of glucagon $(0 \cdot 3 \mathrm{mg}$.).
FIG. 3 right.-(Case 2) Changes in levels of blood glucose, lactate, pyruvate, plasma non-esterified fatty acids, ketones methylmalonic acid, and standard bicarbonate following the ingestion of L-valine (2 g.). Note persistent fall in blood glucose and standard bicarbonate and rise in plasma ketones.

FIg. 3 left.-(Case 2) Changes in levels of blood glucose, lactate, pyruvate, plasma non-esterified fatty acids, ketones, methylmalonic acid, and standard bicarbonate following the ingestion of fat $(30 \mathrm{~g}$.).
FAT LOADING TEST.

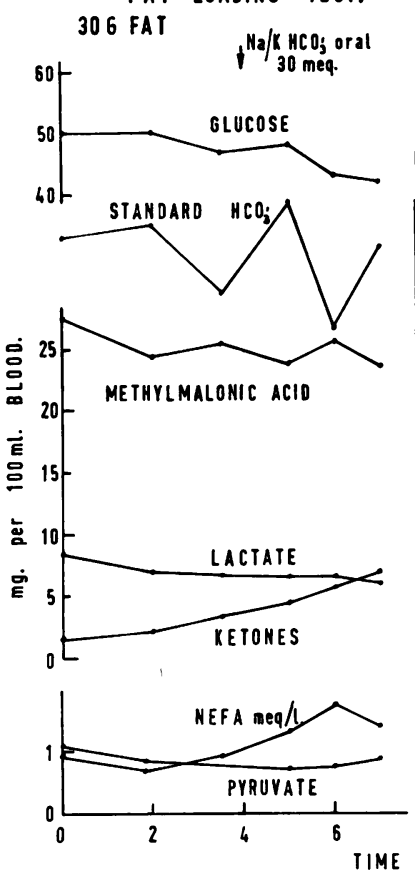

L-VALINE LOADING TEST. 2.06 L-VALINE.

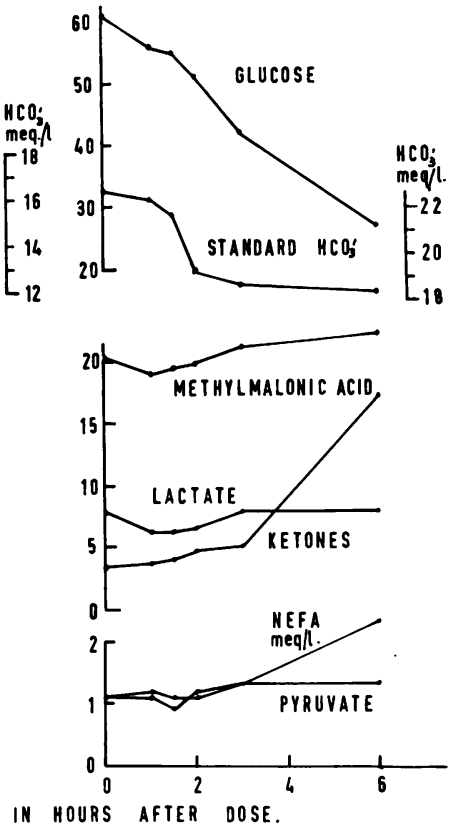

Fig. 3 


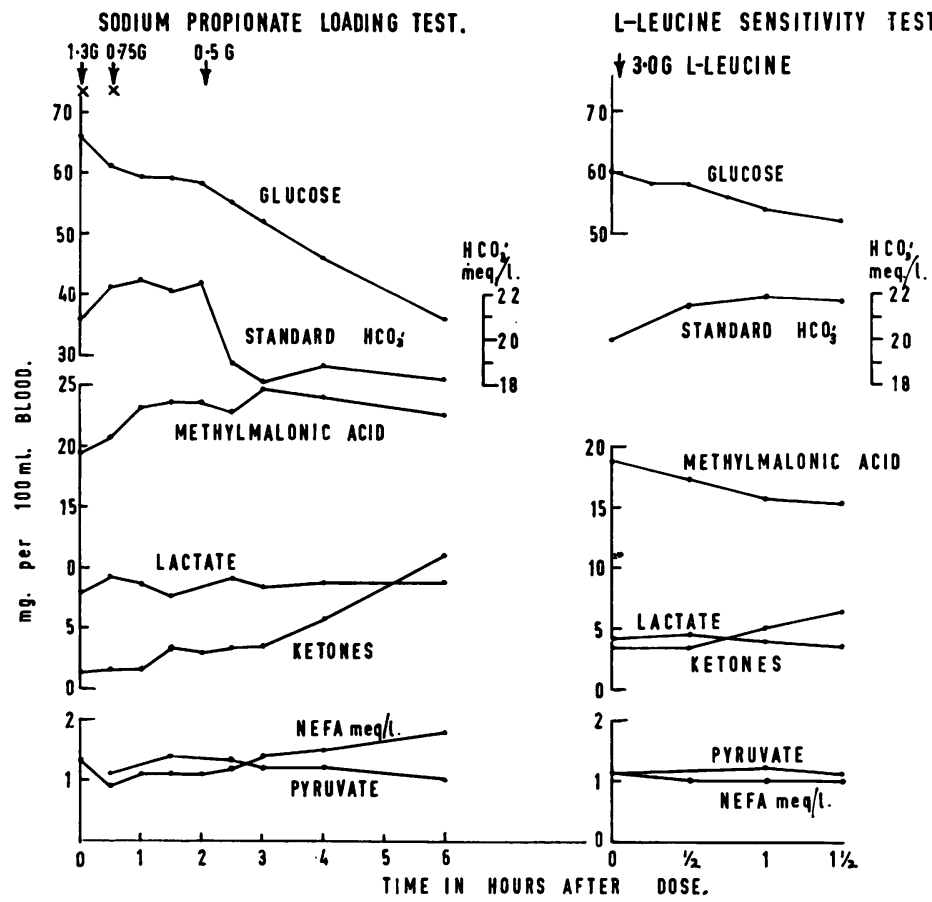

Fig. 4 left.-(Case 2) Changes in levels of blood glucose, lactate, pyruvate, plasma non-esterified fatty acids, ketones methylmalonic acid, and standard bicarbonate following the ingestion of sodium propionate. Note consistent fall in blood glucose and standard bicarbonate and rise in methylmalonic acid and ketones.

FIG. 4 right.-(Case 2) Changes in levels of blood glucose, lactate, pyruvate, plasma non-esterified fatty acids, ketones, and methylmalonic acid following the ingestion of $\mathrm{L}$-leucine $(3 \cdot 0 \mathrm{~g}$.$) .$

rose significantly, as did the plasma ketones, but there was little alteration in the urinary excretion of either. A mild acidosis developed 2 hours after the valine was given and persisted thereafter.

Fat loading test. A similar series of estimations was performed 2, 4, 6, and 8 hours after the administration of a test dose of $30 \mathrm{~g}$. fat as butter and cream, and the results are shown in Fig. 3. The fall in blood glucose was less than that found after the protein meal, nor was the rise in plasma non-esterified fatty acid so great. The plasma methylmalonic acid tended to fall, while the ketone bodies rose, though these changes were not so marked as after the protein load. The changes in the urinary excretion of methylmalonic acid or ketone bodies were not striking. The plasma $\alpha$-ketoglutarate, however, significantly increased from $0.18 \mathrm{mg}$. to $0.30 \mathrm{mg}$./ $100 \mathrm{ml}$. The plasma standard bicarbonate level fell, but rose after her usual dose of $15 \mathrm{mEq}$ each of sodium and potassium bicarbonate.

Leucine. In order to determine whether there was a specific hypersensitivity to leucine, a loading dose of $3.0 \mathrm{~g}$. was given. There was a slight fall in glucose of $8 \mathrm{mg} . / 100 \mathrm{ml} .90$ minutes after the amino acid was given, and no alterations in the levels of lactate, pyruvate, or the free fatty acids. There was, however, a slight fall in methylmalonic acid and a rise in the blood ketones (Fig. 4).

Sodium propionate loading. Since propionic acid is the immediate precursor of methylmalonic acid, it was obviously desirable to attempt a stress test with this substance. Vomiting occurred 10 minutes after an initial load of $1.3 \mathrm{~g}$. sodium propionate dissolved in water. A second amount of $0.75 \mathrm{~g}$. given 40 minutes after the first also induced vomiting. However, a still smaller amount, $0.5 \mathrm{~g}$., given at $2 \frac{1}{4}$ hours after the initial dose was successfully retained. Blood glucose, lactate, pyruvate, and plasma free fatty acids were estimated at hourly intervals for 6 hours after the initial loading dose. The plasma and urinary methylmalonic acid and ketone bodies were also determined. There was a marked and consistent fall in blood glucose from $66 \mathrm{mg}$. to $36 \mathrm{mg}$./ $100 \mathrm{ml}$., with little alteration in either blood lactate or pyruvate levels (Fig. 4). As expected, plasma free fatty acids rose consistently, after a slight initial drop. The level of methylmalonic acid rose after the first dose, showing that some propionate had been absorbed, and thereafter there was an even more marked rise to a peak 


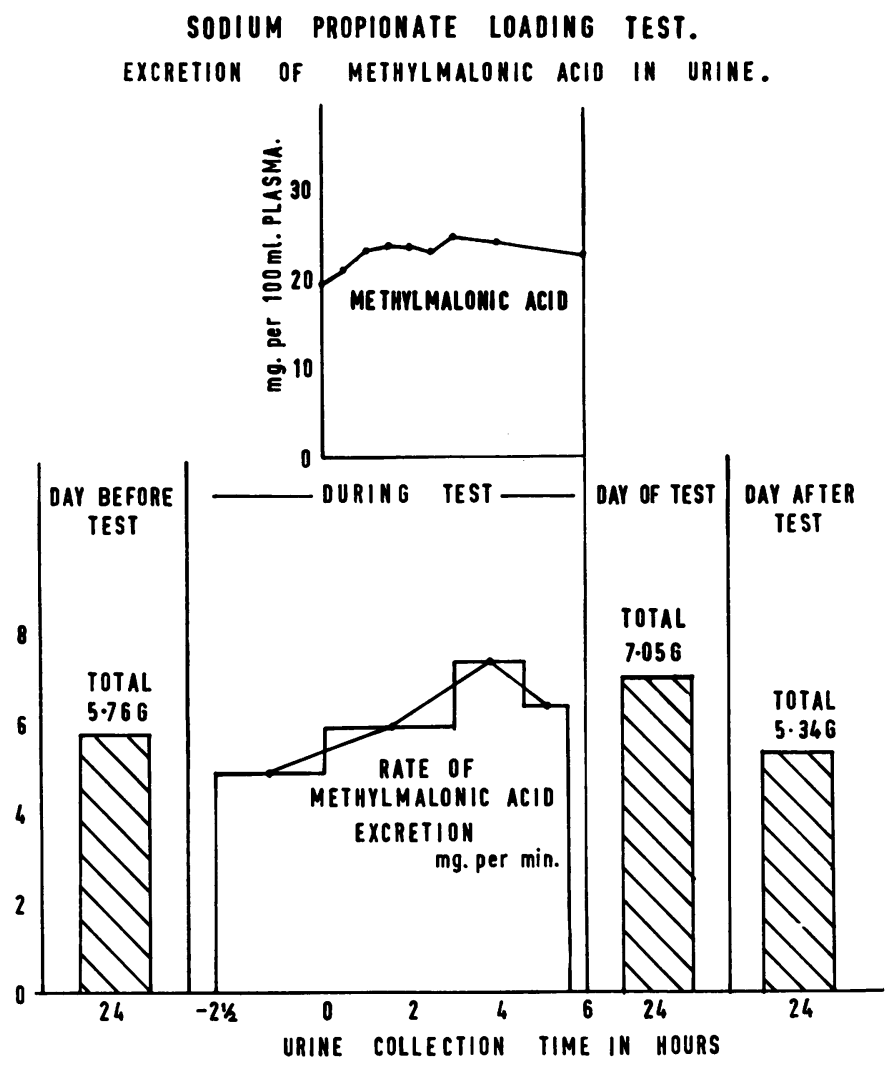

FIG. 5.-(Case 2) The effect of ingestion of sodium propionate on the urinary excretion of methylmalonic acid. Note the increase in total excretion as well as in the rate of excretion of methylmalonic acid.

3 hours after the initial dose. There was a sharp rise also in the plasma ketone bodies. The increase in the level of methylmalonic acid was reflected in an increased rate of excretion of the acid as well as of total methylmalonic acid excretion over the 24-hour period, compared with that of the 24 hours preceding and the 24 hours following the test (Fig. 5). A slight acidosis developed 3 hours after the initial dose was given.

Enzyme assay. Methylmalonyl CoA isomerase is known to be present in the mammalian liver and kidney (Beck, Flavin, and Ochoa, 1957). We have been able to demonstrate it also in rat jejunal mucosa and in human white cells. Its absence in these tissues in cases of methylmalonic aciduria would be a final proof of the site of the metabolic block. Since white cells are readily accessible, these were used for enzyme assay by the method of Stern and Friedmann (1960). White cell homogenates were incubated with propionyl $\mathrm{CoA}$, and ${ }^{14} \mathrm{C}$-labelled $\mathrm{Na}_{2} \mathrm{CO}_{3}$. The methylmalonic, succinic, fumaric, and malic acids formed were separated by paper chromatography and the individual amount of each acid determined from the ${ }^{14} \mathrm{C}$ incorporated in them. Preliminary observations showed that in Case 2, while methylmalonic acid was formed in normal amount, there was a marked deficiency in the subsequent conversion to succinic, fumaric, and malic acids, as compared with cells from normal adults. A full account of these observations and results will be published elsewhere.

\section{Discussion}

Although many of the clinical and biochemical findings in this condition were consistent with a diagnosis of primary renal tubular acidosis, there were some puzzling features. Its persistence despite treatment suggested the adult form of the disease, yet the condition, at least in the second child, was apparently congenital. Secondly, whereas in renal tubular acidosis, hyperchloraemia is always found, in this condition the plasma chloride level was normal and sometimes decreased especially in periods of acidosis. Thirdly, the metabolic 
acidosis was accompanied by ketosis, often severe, and this is not a feature of primary renal tubular acidosis. Lastly, the excretion of an acid urine below $p \mathrm{H} 6.0$ when the plasma $p \mathrm{H}$ and bicarbonate ion concentration were normal is not characteristic of primary renal tubular acidosis. The last observation suggested the possibility that the acidosis was due to an increase in the blood levels of one or more of the organic acids.

Nature of metabolic defect. Methylmalonic acid as the CoA derivative (Fig. 6) is an intermediate in the metabolism of certain dietary amino acids, especially methionine, and of those fats, occurring only in very small quantity in the normal diet, which contain fatty acids with an odd number of carbon atoms (Fig. 7). Isoleucine, valine, and threonine, in addition, probably form this acid, which may also arise by the katabolism of such pyrimidines as thymidine. The accumulation of this non-nitrogencontaining organic acid in the plasma and CSF, together with the massive daily excretion in the urine of this acid, which is not normally found in detectable amount in either blood or urine, suggests that the block is in the conversion of methylmalonyl CoA to succinyl CoA, the free methylmalonic acid being presumably formed from the CoA derivative. The methylmalonyl CoA, form a, produced initially from propionyl CoA, is converted by the enzyme methylmalonyl CoA racemase to its isomer, form $b$ (Fig. 7). The latter can then be transformed to succinyl CoA by an enzyme, methylmalonyl CoA isomerase, together with a cobamide coenzyme, which is a derivative of vitamin B12. The defect could be either in a lack of the cobamide coenzyme or in the methylmalonyl $\mathrm{CoA}$ isomerase itself. It has recently been shown that in pernicious anaemia due to vitamin $\mathrm{B} 12$ deficiency, methylmalonic acid is excreted in the urine (Marston, Allen, and Smith,

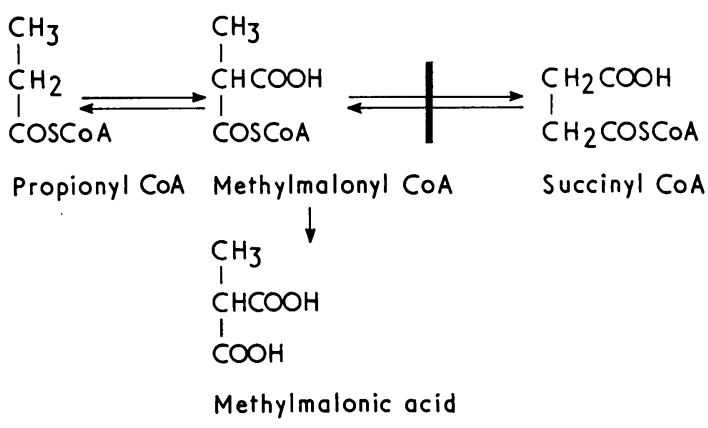

FIG. 6.-Formation of methylmalonic acid, and site of metabolic block.

1961; Cox and White, 1962; White, 1962; Barness, Young, Mellman, Kahn, and Williams, 1963). This must result from a decreased activity of methylmalonyl CoA isomerase resulting from the cobamide deficiency. The amount of methylmalonic acid excreted in our case is far in excess of the amounts known to be excreted in cases of pernicious anaemia, and furthermore, in the second patient the serum vitamin B12 was actually raised though the folate level was within normal limits, so that B12 deficiency cannot be the cause. It seems also unlikely that there is a deficiency of the specific coenzyme since this would also result in a relatively small excretion of methylmalonic acid. It is probable, therefore, that the methylmalonyl CoA isomerase is at fault.

Renal function. In the second child (Case 2), as shown by the low urea and creatinine clearances and low hydrogen ion clearance index, renal function was impaired at least by the sixth month of life. However, both urea and creatinine clearances had greatly improved by 6 years of age (Table). Whether this represented a real change or only a

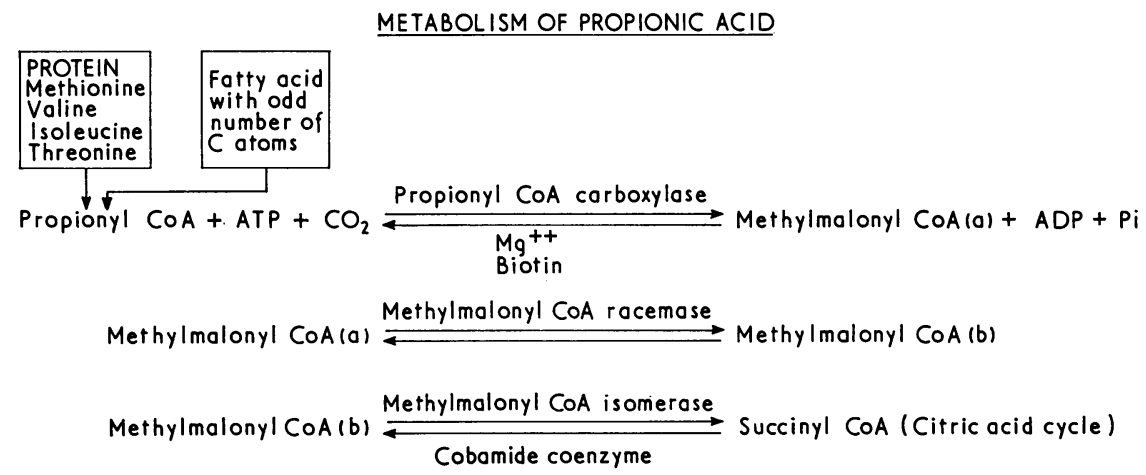

FIG. 7.-Pathway of propionate metabolism, showing site of metabolic block and formation of methylmalonic acid. 


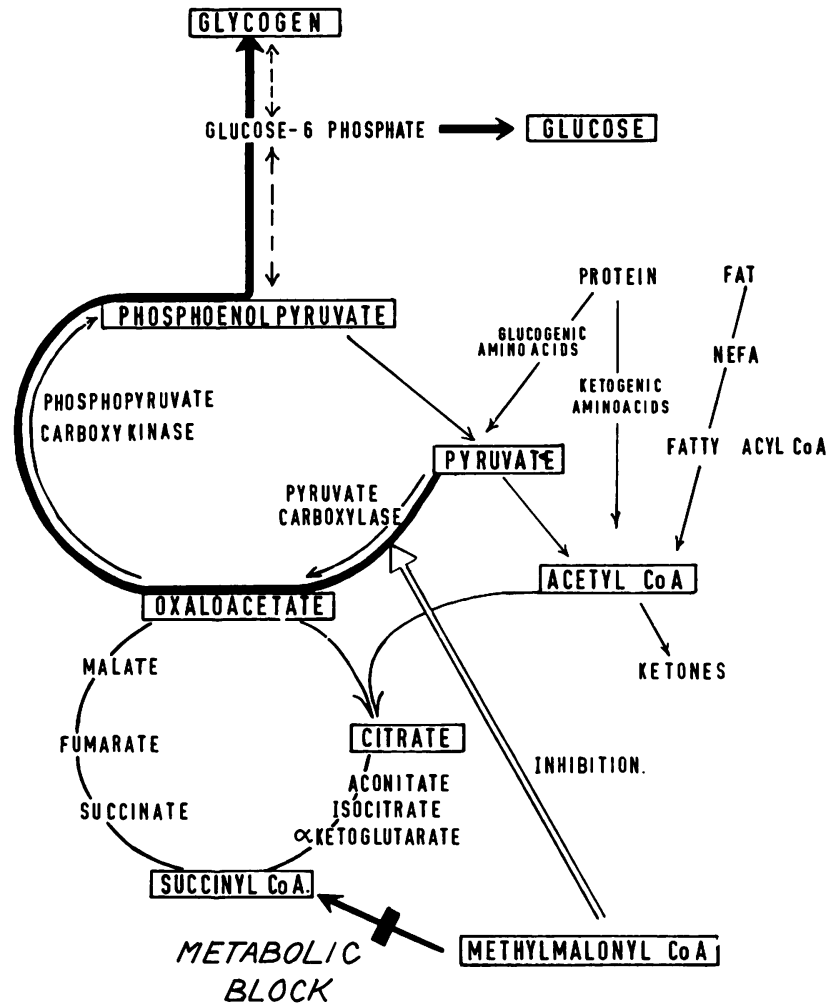

Fig. 8.-The effect of the enzymatic block on the main pathway of hepatic gluconeogenesis.

maturation of function is not certain, but even at the age of 6 years, urea clearance was still below the normal level. Similarly, in the first child, the urea clearance was impaired by $8 \frac{1}{2}$ months of age, and at necropsy, both kidneys showed an unusual histological appearance consistent with an arrested renal development. In contrast to the second case, however, at no time was the ability to acidify the urine apparently impaired. These findings are not easy to explain. Corley and Rose (1926) have shown that the administration of methylmalonic acid to rabbits results in a slightly increased retention of non-protein nitrogen. This may account in part for the diminished renal function in the present cases. It is perhaps more likely that methylmalonyl CoA directly affects hydrogen ion transport, possibly because of deficient $\mathrm{CO}_{2}$ formation in the renal tubular cell, due to the nature of the metabolic block.

Stress tests of metabolic pathways. Carbohydrate tolerance and glycogen stores appeared to be normal, though it is interesting to note that in the glucose tolerance test the total plasma ketones fell as the blood glucose rose, as would be expected, but the levels of the ketone bodies were within normal limits throughout the test.

The effects of a protein meal and of ingestion of valine were similar. The marked fall in blood glucose following the intake of protein or of the amino acid requires some explanation. It could not have been due to an inability to mobilize glucose from glycogen since injection of glucagon produced a normal response. It might have resulted from an inhibition of one or more steps in the pathway of gluconeogenesis, which is now held to play a more important role than glycogenolysis in the maintenance of blood glucose. Views on the metabolic pathway of gluconeogenesis from protein and fat via pyruvate have recently been modified (Utter, Keech, and Scrutton, 1964). Pyruvate formed from amino acids and fatty acids is converted first to oxaloacetate, and then to phosphoenolpyruvate, from which glucose is formed by a reversal of the usual forward reactions (Fig. 8). The first of these steps is mediated by pyruvate carboxylase which 
has been shown by Utter et al. (1964) to be a key enzyme in gluconeogenesis from pyruvate and which is effectively inhibited by methylmalonyl CoA. Thus, the accumulation intracellularly of the latter in methylmalonic aciduria would, on this basis, seriously diminish gluconeogenesis, and this effect would be accentuated after a protein meal or after valine because of the increased formation of methylmalonyl CoA from the precursor amino acids (Fig. 8). The plasma level of methylmalonic acid did not in fact rise during these stress tests, but this may not accurately reflect the immediate rise of intracellular methylmalonyl CoA, due to a slower conversion of the CoA derivative to the free acid. It is probably the latter rather than the former which is easily diffusible out of the cell. This possibility is supported by the observation that, though the plasma methylmalonic acid level did not rise, there was an increased rate of urinary excretion. It might be expected that any inhibition of pyruvate carboxylase would result in a rise in the blood level of pyruvate after protein or valine ingestion. There was, in fact, little change, and this may have been due to its further conversion to acetyl $\mathrm{CoA}$ and thereafter into ketone bodies.

Metabolic acidosis. The metabolic acidosis present in this condition can be only partly explained by the plasma level of methylmalonic acid which would only amount to about $2 \mathrm{mEq} / 1$. A possible explanation lies in the nature of the metabolic defect. Because of the block in the conversion of methylmalonyl CoA to succinyl CoA, there may be a decreased turnover in the citric acid cycle of which succinyl CoA is a component. It follows that the metabolic acidosis which is present at all times may be mainly due to the primary reduction in bicarbonate formation by the citric acid cycle, and this may be a bigger factor than the lowering of the plasma bicarbonate by the level of methylmalonic acid and even ketone bodies. For this reason, in the second patient, the alkali therapy was changed from citrate to bicarbonate, since the latter would make up the bicarbonate deficit directly, without needing to be metabolized through the citric acid cycle, as the former must require.

The severe acidosis during periods of exacerbation with infection was associated not so much with an increased level of methylmalonic acid as with a large increase in ketone bodies. An excessive production of the latter results from any conspicuously increased utilization of fats by the liver, e.g. in diabetes or infection. Wieland, Weiss, and EgerNeufeldt (1964) have shown that palmityl CoA, formed from the fatty acid, inhibits citrate synthase, thus blocking the citric acid cycle, and shifting acetyl CoA towards the formation of ketone bodies. In the present instance, there is an additional factor tending to increase ketosis. The inhibition of gluconeogenesis by the high concentration of methylmalonyl CoA results in an inability to maintain blood glucose levels and therefore in an even greater need for utilization of fats and an even greater formation of ketone bodies than is usual during any stress, e.g. infection. Another factor that may increase ketosis is the fixation of CoA as methylmalonyl $\mathrm{CoA}$, which will diminish the amount of free CoA. The need to augment available CoA is met by the diversion of acetyl CoA formed from the fatty acids and pyruvate towards the formation of ketone bodies which will liberate free CoA. The development of this ketosis is thus minimized by prompt administration of glucose, and this explains its beneficial effect in our patient at the onset of an infection. There is an interesting parallel between the severe acidosis and ketosis in these cases resulting from infection and the severe ketosis occurring in diabetes mellitus. Clinically the conditions resemble each other, but in the former there is a low blood glucose, whereas in the latter the blood glucose is much increased.

Following the protein load also there was a sixfold rise in plasma ketones as well as hypoglycaemia, and this accounted for the increased metabolic acidosis which occurred. The mechanism of ketosis is probably the same as that operating during periods of stress from infection. The inhibition of gluconeogenesis by the high concentration of methylmalonyl CoA resulted in hypoglycaemia which stimulated mobilization of fat. Although a lowering of the blood glucose was induced by the oral ingestion of leucine, the response was not characteristic of that seen in leucine hypersensitivity. As the test was not prolonged for longer than 3 hours, the results obtained were not strictly comparable with either the protein or valine loading tests. The rise in plasma ketone level during that time was relatively slight, and there was no increase in the metabolic acidosis.

As might be expected, the ingestion of sodium propionate, since it is directly converted into methylmalonyl CoA, resulted in a significant rise in the plasma level of methylmalonic acid, in contrast to the finding with ingestion of amino acids or protein. The rise was accompanied by a marked increase in the rate of excretion of the acid as well as an absolute increase in the amount excreted in the 24 hours following the dose. In addition, sodium propionate also exerted the marked hypoglycaemic effect shown by protein and valine. Since pro- 
pionate, like lactate or acetate, is normally readily metabolized to bicarbonate, the plasma bicarbonate level might be expected to rise, or at least be maintained, whereas it actually fell after propionate ingestion. Furthermore, the urine remained acid, instead of becoming alkaline, as should normally occur. All these results afford strong support for the conclusion that the site of the metabolic block is in the conversion of methylmalonyl CoA to succinyl CoA.

Levels of methylmalonic acid in CSF and plasma. The level of the acid in CSF, even higher than that in plasma, suggests the possibility that it may actually be produced in the brain. This is in accordance with recent experimental evidence obtained by the injection of ${ }^{14} \mathrm{C}$-labelled propionate into the carotid artery of sheep and rats, which strongly supports the belief that in these animals, the brain metabolizes propionate to succinic acid via methylmalonyl CoA (O’Neal, Koeppe, and Williams, 1966).

Genetics. Since the metabolic acidosis was present from the earliest days of life in both children, the condition is an inherited, inborn error of metabolism. The affected infants were one male and one female and, as in neither family were the parents affected, the condition is presumably inherited as an autosomal recessive. In both cases neither the parents nor the unaffected sib or sibs were excreting methylmalonic acid. In an attempt to detect the heterozygote state, a test dose of sodium propionate was given to the parents of Case 2 . This resulted in the excretion by the mother only of a small amount of methylmalonic acid, but no acid could be detected in the plasma after the dose, nor were there any other changes. There were no changes following a loading dose given to the father.

\section{Summary}

Two children of unrelated families are described who failed to thrive, and who manifested from the earliest days of life a persistent metabolic acidosis, punctuated by more severe crises of acidosis with ketosis, set off by infection, often trivial. In both, the acidosis was treated with alkalis, and in the severe episodes intravenous therapy was always required.

The first, a boy, in whom the diagnosis was made by an examination of his stored plasma 7 years after death, became mentally and physically retarded, and died at 2 years of age in an acute metabolic acidosis with ketosis. The second, a girl, in whom the definitive diagnosis was not made till she was $5 \frac{1}{2}$ years old, is now a well child, though still needing alkali therapy. In both cases the urea and creatinine clearances were impaired, and in the second case there was also a low hydrogen ion clearance index. The first showed on several occasions moderate aminoaciduria, mainly glycine. The differences between this condition and primary renal tubular acidosis are discussed.

An examination of the urine of the second patient showed that she was excreting a large amount of methylmalonic acid, an intermediate in the metabolism of some amino acids of dietary origin, and of fatty acids with an odd number of carbon atoms. In both cases high plasma levels of the acid were found. In the second case, the level in CSF was as high as in the plasma, indicating that methylmalonic acid was being produced in the brain.

The accumulation of methylmalonic acid in the plasma and CSF suggested a metabolic block in the conversion of methylmalonyl coenzyme $A$ to succinyl coenzyme A, a step catalyzed by the enzyme methylmalonyl coenzyme $A$ isomerase, and this was supported by the effect of ingestion of sodium propionate. Stress tests of metabolism revealed that with a loading dose of either protein, valine, or propionate, hypoglycaemia and ketosis were induced, resulting from a secondary inhibition of gluconeogenesis by methylmalonyl CoA. Preliminary experiments showed a marked deficiency of the enzyme in leucocytes from the affected subject compared with those from normal people. The condition is therefore an inborn error of metabolism inherited as an autosomal recessive.

It is concluded from these two cases that without adequate treatment, there may be physical and mental retardation, and even death during an acute crisis. With adequate treatment, especially during the crisis, these may be averted.

The unfailing co-operation of the nursing and junior medical staff is gratefully acknowledged. In particular we would like to thank Dr. M. N. Buchanan, who as Resident Medical Officer was responsible for the dayto-day care of the second case during her very severe episode when methylmalonic acid was first found in the urine; and Miss V. D. Ambridge, Research Sister, for her assistance in the metabolic tests.

\section{REFERENCES}

Barness, L. A., Young, D., Mellman, W. J., Kahn, S. B., and Williams, W. J. (1963). Methylmalonate excretion in a patient with pernicious anemia. New Engl. F. Med., 268, 144.

Beck, W. S., Flavin, M., and Ochoa, S. (1957). Metabolism of propionic acid in animal tissues. III. Formation of succinate. F. biol. Chem., 229, 997.

Corley, R. C., and Rose, W. C. (1926). The nephropathic action of the dicarboxylic acids and their derivatives. V. Alkyl-, hydroxy-, and keto-acids. f. Pharmacol. exp. Ther., 27, 165.

Cox, E. V., and White, A. M. (1962). Methylmalonic acid excretion: an index of vitamin- $\mathrm{B}_{12}$ deficiency. Lancet, $2,853$. 
Giorgio, A. J., and Plaut, G. W. E. (1965). A method for the colorimetric determination of urinary methylmalonic acid in pernicious anaemia. f. Lab. clin. Med., 66, 667.

Marston, H. R., Allen, S. H., and Smith, R. M. (1961). Primary metabolic defect supervening on vitamin $\mathrm{B}_{12}$ deficiency in the sheep. Nature (Lond.), 190, 1085.

Nordmann, R., Gauchery, O., du Ruisseau, J. P., Thomas, Y., and Nordmann, J. (1954). Détermination des acides organiques de l'urine par chromatographie sur papier. C.R. Acad. Sci. (Paris), 238, 2459.

O'Neal, R. M., Koeppe, R. E., and Williams, E. I. (1966). Utilization in vivo of glucose and volatile fatty acids by sheep brain for the synthesis of acidic amino acids. Biochem. $\mathcal{F} ., 101,591$.

Peonides, A., Levin, B., and Young, W. F. (1965). The renal excretion of hydrogen ions in infants and children. Arch. Dis. Childh., 40, 33.

Stern, J. R., and Friedmann, D. C. (1960). Vitamin $B_{12}$ and methyl malonyl CoA isomerase. - I. Vitamin $B_{12}$ and propionate metabolism. Biochem. biophys. Res. Commun., 2, 82.

Tanayama, S., and Ui, M. (1963). Determination of small amounts of ketone bodies in blood. Chem. pharm. Bull., 11, 835. (Analyt. Abstr., 1964, 11, no. 4449.)

Utter, M. F., Keech, D. B., and Scrutton, M. C. (1964). A possible role for acetyl $\mathrm{CoA}$ in the control of gluconeogenesis. In Advances in Enzyme Regulation, ed. G. Weber, vol. 2, p. 49. Pergamon Press, Oxford.

White, A. M. (1962). Vitamin $B_{12}$ deficiency and the excretion of methylmalonic acid by the human. Biochem. F., 84, 41P.

Wieland, O., Weiss, L., and Eger-Neufeldt, I. (1964). Enzymatic regulation of liver acetyl-CoA metabolism in relation to ketogenesis. In Advances in Enzyme Regulation, ed. G. Weber, vol. 2, p. 85 . Pergamon Press, Oxford.

\section{Appendix}

\section{Estimation of Methylmalonic Acid}

Principle. Methylmalonic acid is allowed to react with diazotized p-nitroaniline and the optical density of the emerald green colour which develops after making alkaline with $\mathrm{NaOH}$ is measured at $620 \mathrm{~m} \mu$ (Giorgio and Plaut, 1965).

Reagents. p-nitroaniline solution: $0.075 \mathrm{~g}$. dissolved in $100 \mathrm{ml} .0 \cdot 2 \mathrm{~N} \mathrm{HCl}$, and kept in the dark.

$4 \mathrm{M}$ formate buffer solution $\mathrm{pH3}$, prepared from formic acid and sodium hydroxide.

Buffer reagent: $4 \mathrm{M}$ formate buffer ( $5 \mathrm{ml}$ ) is mixed with $2 \mathrm{~N} \mathrm{NaOH}$ solution $(9 \mathrm{ml}$.) and water $(1 \mathrm{ml}$.).

Sodium nitrite solution: $0.66 \mathrm{~g}$. in $10 \mathrm{ml}$. water, prepared fresh just before use.

Diazo reagent: To $10 \mathrm{ml}$. p-nitroaniline is added $0 \cdot 1$ $\mathrm{ml}$. of the sodium nitrite solution at room temperature, the mixture allowed to stand for exactly 2 minutes and then $1.5 \mathrm{ml}$. dilute buffer reagent added, and after rapid mixing, $1 \mathrm{ml}$. is immediately taken for the colour reaction.

Methylmalonic acid standard. Prepared by dissolving $20 \mathrm{mg}$. of the acid in water, making alkaline with $1 \mathrm{ml}$. $\mathrm{N} \mathrm{NaOH}$ solution, and adding water to a final volume of $100 \mathrm{ml}$.

Procedure. Because of the high concentration of methylmalonic acid in the patient's urine, this was always diluted 1 in 100 before estimation. To $0.1 \mathrm{ml}$. diluted urine in a $12.5 \times 1.5 \mathrm{~cm}$. test-tube is added $0.9 \mathrm{ml}$. water, followed by $1 \mathrm{ml}$. of freshly prepared diazo reagent, with mixing. The tube and contents are placed in a large water bath at $91.5^{\circ} \mathrm{C}$. and allowed to remain for 90 seconds. The test-tube is then cooled rapidly by allowing it to stand in a water bath at $15-18^{\circ} \mathrm{C}$., for 1-3 minutes, after which $1 \mathrm{ml} .2 \mathrm{~N} \mathrm{NaOH}$ is added and mixed. After standing for about 10 minutes, the optical density at $620 \mathrm{~m} \mu$ is measured. The colour is stable for several hours. A standard and reagent blank are treated in exactly the same way for every series of urines. It is essential to adhere strictly to these conditions for reproducibility. Optical density is proportional to concentration over a wide range, allowing for a direct calculation of the concentration of the unknown.

For estimation in plasma, serum, or CSF, $0.05 \mathrm{ml}$. is added to $1.4 \mathrm{ml}$. water in a centrifuge tube, followed by $0.05 \mathrm{ml}$. of $0.05 \mathrm{M}$ acetic acid. The tube is covered with a rubber stopper carrying a hypodermic needle, placed in boiling water for 7 minutes, then cooled, the needle removed, and the contents mixed thoroughly by inversion. After centrifugation, $1 \mathrm{ml}$. aliquots are removed for estimation as above. A normal plasma as a blank and a standard made by the addition of methylmalonic acid to this plasma in a final concentration of $20 \mathrm{mg}$. $/ 100 \mathrm{ml}$. are treated in exactly the same way. The optical density at $620 \mathrm{~m} \mu$ is determined and the concentration of methylmalonic acid is calculated as follows:

Concentration of methylmalonic acid (mg./100 ml.)

$$
=\frac{\text { OD unknown plasma-OD normal plasma }}{\text { OD standard in normal plasma-OD normal plasma }} \times 20
$$

Detection of methylmalonic acid on paper. The method used was an adaptation of the diazo reaction in solution. After chromatography, the dried paper is sprayed with or dipped into the fresh diazo reagent. It is then heated in an oven at $100^{\circ} \mathrm{C}$. for 1 minute, when a yellow or yellowish-brown spot develops, which after spraying with $2 \mathrm{~N} \mathrm{NaOH}$ solution turns emerald green. 